\title{
ANALISIS KELAYAKAN PENGUMPULAN TANDAN BUAH SEGAR KELAPA SAWIT MENGGUNAKAN SEWA ANGKUTAN ARMADA TRUK DI KECAMATAN KOTAWARINGIN LAMA KABUPATEN KOTAWARINGIN BARAT
}

\author{
${ }^{1}$ Ario Sandika Putra, ${ }^{2}$ Evi Feronika, ${ }^{3}$ Trisna Anggreini \\ ${ }^{1}$ Alumni Program Studi Agribisnis, Jurusan Sosial Ekonomi, Fakultas Pertanian \\ ${ }^{2,3}$ Staf Pengajar Program Stud.i Agribisnis, Jurusan Sosial Ekonomi, Fakultas \\ Pertanian
}

\begin{abstract}
ABSTRAK
Penelitian ini bertujuan untuk mengetahui gambaran umum dan menganalisis kelayakan usaha pengumpul tandan buah segar Kelapa Sawit di Desa Sukabulin Kecamatan Kotawaringin Lama Kabupaten Kotawaringin Barat yang di analisis dengan metode analisis kelayakan finansial yaitu nilai bersih sekarang, tingkat pengembalian internal, rasio biaya manfaat, dan periode pengembalian modal. Penelitian ini adalah penelitian kuantitatif. Subjek penelitian ini adalah pedagang pengumpul, dan objek penelitian ini adalah usaha pengumpulan tandan buah segar Kelapa Sawit menggunakan sewa angkutan armada truk. Metode pengumpulan data dilakukkan dengan teknik wawancara dan observasi (pengamatan langsung). Teknik analisis data adalah analisis kuantitatif dilakukkan untuk menganalisis kelayakan aspek finansial usaha pengumpulan tandan buah segar Kelapa Sawit. Hasil penelitian ini menunjukkan bahwa usaha pengumpulan tandan buah segar Kelapa Sawit memiliki aspek pendukung seperti aspek hukum, aspek pasar, aspek teknis, aspek manajemen, dan aspek sosial dan lingkungan. Hasil analisis kelayakan finansial menunjukkan hasil yang positif, sehingga usaha pengumpulan tandan buah segar Kelapa Sawit ini layak untuk diusahakan dan dapat dikembangkan untuk kedepannya. Hal ini ditunjukkan oleh hasil nilai bersih sekarang sebesar Rp 201.232.547, tingkat pengembalian internal sebesar $34,9 \%$, rasio biaya manfaat sebesar $1,08 \%$ dan periode pengembalian modal 2,4 atau selama 2 tahun 4 bulan. Hasil analisis kelayakan finansial periode pengembalian modal yaitu 2 tahun 4 bulan. Nilai tersebut lebih pendek jika dibandingkan dengan umur dan target usaha yaitu selama 5 tahun. Sehingga pedagang pengumpul tandan buah segar Kelapa Sawit dapat menambah armada pengangkutan seperti truk, dengan membeli secara kredit maupun tunai, dan bekas maupun baru.
\end{abstract}

Kata Kunci : Tandan Buah Segar Kelapa Sawit, Kelayakan Finansial

\begin{abstract}
The purpose of research is find out the general picture and analyze the feasibilityof thebusiness of collecting palm fresh fruit In Sukabulin Village, Kotawaringin Lama District, West Kotawaringin Regency, which is analyzed by financial feasibility
\end{abstract}


analysis method namely Net Present Value, Internal Rate of Return, Benefit Cost Ratio, and Payback Period.

This research is quantitative research. The subject of this research is the collector trader, and the object of this research is the effort to collect fresh fruit containers of Palm Oil using truck fleet transportation leases. Data collection method is done by interview and observation techniques (direct observation). Data analysis techniques are quantitative analysis carried out to analyze the feasibility of financial aspects of palm oil fresh fruit collection efforts.

The results of this study showed that the effort to collect fresh fruit marks of palm oil has supporting aspects such as legal aspects, market aspects, technical aspects, management aspects, and social and environmental aspects. The results of financial feasibility analysis show positive results, so that the effort to collect palm oil fresh fruit is worth trying and can be developed for the future. This is indicated by the Net Present Value of Rp 201,232,547, Internal Rate of Return, of 34.9\%, Benefit Cost Ratio of $1.08 \%$ and Payback Period of 2.4 or for 2 years and 4 months.

The result of financial feasibility analysis payback period is 2 years 4 months. The value is shorter when compared to the age and business target of 5 years. So that as a trader collecting palm fresh fruit Palm Oil can increase the transport fleet such as trucks, by buying on credit or cash, and second and new.

Keywords: Oil Palm Fresh Fruit Bunches, Financial Feasibility.

\section{PENDAHULUAN}

\section{Latar Belakang}

Kelapa Sawit di Kecamatan Kotawaringin Lama yang berkisar antara 1-10 ha menghasilkan produktivitas yang minim sehingga menyebabkan penjualannya sulit dilakukan apabila langsung menjual ke pabrik Kelapa Sawit (PKS), selain itu banyak persyaratan yang harus dipenuhi, lokasi PKS yang jauh dan keterbatasan alat transportasi pengangkutan menambah kesulitan bagi petani jika ingin menjual hasil produksinya ke pabrik langsung. Oleh karena itu petani Kelapa Sawit di Kecamatan Kotawaringin Lama menjual hasil TBS nya melalui lembaga pemasaran seperti pedagang pengumpul TBS Kelapa Sawit.
Usaha pengumpulan TBS Kelapa Sawit adalah salah satu usaha agribisnis tingkat desa yang bergerak dibidang cross dock untuk pengumpulan hasil TBS Kelapa Sawit. Salah satu pedagang pengumpul TBS Kelapa Sawit di Kecamatan Kotawaringin Lama adalalah Bapak Muhtar. Selama ini usaha pengumpulan TBS Kelapa Sawit Bapak Muhtar dalam menjual hasil pengumpulan TBS nya ke PKS selalu menggunakan alternatif sewa angkutan truk. Mahalnya biaya sewa angkutan truk tentu akan sangat berpengaruh terhadap biaya operasional yang akan dikeluarkan, dan pendapatan.

\section{Tujuan Penelitian}

Penelitian ini bertujuan untuk : Menganalisis kelayakan usaha pengumpulan Tandan Buah Segar 
Kelapa Sawit pengangkutan menggunakan sewa angkutan armada truk di Kecamatan Kotawaringin Lama.

\section{METODE PENELITIAN}

\section{Lokasi dan Waktu Penelitian}

Penelitian ini dilaksanakan di
Desa Sukabulin Kecamatan
Kotawaringin Lama Kabupaten
Kotawaringin Barat, Provinsi
Kalimantan Tengah. Penentuan lokasi
penelitian dilakukan secara sengaja
(purposive), dengan pertimbangan
karena usaha pengumpulan TBS
Kelapa Sawit tersebut masih
menggunakan alternatif
pengangkutan TBS Kelapa Sawit nya
menggunakan sewa angkutan truk,
sehingga membutuhkan biaya
pengangkutan yang besar. Oleh
karena itu peneliti ingin mengetahui
lebih lanjut kelayakan usaha
pengumpulan TBS Kelapa Sawit
pengangkutan dengan menggunakan
sewa angkutan truk. Kegiatan
penelitian ini akan dilaksanakan
selama 3 (tiga) bulan.

\section{Pengumpulan Data}

Data primer yang terkumpul diperoleh melalui metode observasi (pengamatan langsung), dan metode wawancara dengan menggunakan kuesioner. Data sekunder diperoleh dari studi kepustakaan atau studi literatur.

\section{Analisis Data}

Analisis kelayakan usaha pengumpulan Tandan Buah Segar Kelapa Sawit pengangkutan menggunakan sewa angkutan armada truk di Desa Sukabulin Kecamatan Kotawaringin Lama Kabupaten Kotawaringin Barat menggunakan 4 metode sebagai berikut:

1. Net Present Value (NPV)

Rumus umum yang digunakan dalam perhitungan NPV adalah:

$$
\begin{aligned}
& N P V=\sum_{i=1}^{n} N B_{i}(1+i)^{-n} \\
& \text { atau } \\
& N P V=\sum_{i=1}^{n} \frac{N B_{i}}{(1+i)^{n}} \\
& \text { atau } \\
& N P V=\sum_{i=1}^{n} \overline{B_{i}}-\overline{C_{t}}=\sum_{i=1}^{n} N \overline{B_{i}}
\end{aligned}
$$

Keterangan :

$\mathrm{NB}=$ Net Benefit $=$ Benefit - cost (Biaya investasi + Biaya operasi)

$\mathrm{B}_{\mathrm{i}}=$ Benefit yang telah didiskon

$\mathrm{C}_{\mathrm{i}}=$ Cost yang telah didiskon

$\mathrm{i}=$ Diskon faktor

$\mathrm{n}$ = Tahun (waktu)

Keputusan :

NPV >0 : Proyek /usaha layak dijalankan

NPV $=0$ : Proyek/usaha berada di dalam keadaan BEP dimana $\mathrm{TR}=\mathrm{TC}$ dalam bentuk persent value NPV < 0 : Proyek /usaha tidak layak dijalankan

\section{Internal Rate of Return} (IRR)

Internal Rate of Return (IRR) adalah salah satu metode untuk mengukur tingkat investasi. Untuk mengetahui Internal Rate of 
Return (IRR) suatu usaha dapat digunakan parameter adalah :

$$
\mathrm{IRR}=i_{1}+\frac{N P V_{1}}{\left(N P V_{1}-N P V_{2}\right)}\left(i_{2}-i_{1}\right)
$$

Keterangan :

$$
\mathrm{i}_{1}=\text { Tingkat }
$$

bunga terendah yang memberikan nilai NPV positif

$\mathrm{i}_{2} \quad=\quad$ Tingkat bunga terendah yang memberikan nilai NPV negatif

NPV1 = Nilai pada tingkat bunga terendah dengan NPV positif

NPV2 = Nilai pada tingkat bunga terendah dengan NPV negatif

Keputusan :

Jika IRR > Tingkat Bunga maka usaha layak untuk dilakukan

Jika IRR < Tingkat Bunga maka usaha tidak layak untuk dilakukan

\section{Benefit Cost Ratio (B/C}

Ratio)

Benefit Cost Ratio (B/C Ratio) adalah ukuran perbandingan antara pendapatan $($ Benefit $=\mathrm{B}$ ) dengan total biaya produksi $($ Cost $=\mathrm{C})$. Dalam batasan besaran nilai $\mathrm{B} / \mathrm{C}$ dapat diketahui apakah suatu usaha menguntungkan atau tidak. Untuk mengetahui Benefit Cost Ratio (B/C Ratio) suatu usaha dapat digunakan parameter adalah:

$\mathrm{B} / \mathrm{C}$ Ratio $=\frac{\sum_{t=1}^{n} \frac{B_{t}-C_{t}}{(1+i)^{t}}}{\sum_{t=1}^{n} \frac{C_{t}-B_{t}}{(1+i)^{t}}}$

Keterangan:

$\mathrm{B}_{\mathrm{t}}=$ Manfaat (Benefit) pada tahun ke-t

$\mathrm{C}_{\mathrm{t}}=$ Biaya $($ Cost $)$ pada tahun ke-t

i $=$ Discount Factor

$\mathrm{t}=$ Umur proyek

Indikator $N E T B / C$

Ratio adalah :

- Jika Net B/C > 1, maka proyek layak (go) untuk dilaksanakan - Jika Net B/C $<1$, maka proyek tdk layak (not go) untuk dilaksanakan

\section{Payback Period (PBP)}

Payback Period (PBP) adalah jangka waktu yang diperlukan untuk mengembalikan modal suatu investasi, yang dihitung dengan arus kas bersih. Arus kas bersih adalah selisih antara pendapatan dan pengeluaran pertahun. PBP biasanya dinyatakan dalam jangka waktu per tahun.

$\mathrm{PP}=\frac{\text { Investasi }}{\text { Kas Bersih/tahun }} \times 1$ tahun

\section{HASIL DAN PEMBAHASAN}

Kelayakan finansial Usaha Pengumpulan TBS Kelapa Sawit Bapak Muhtar ini dapat dilihat dari beberapa kriteria penilaian investasi yaitu Net Present Value (NPV), B/C Ratio, Internal Rate of Return (IRR) dan Payback Period (PBP). Hasil cashflow pada Usaha Pengumpulan TBS Kelapa Sawit Bapak Muhtar ini 
menunjukkan hasil yang tertera pada

Tabel 1.

Tabel 1. Hasil Analisis Finansial Usaha Pengumpulan TBS Kelapa Sawit Bapak Muhtar, Tahun 2019

\begin{tabular}{|c|c|c|c|}
\hline Kriterian & Hasil & Keterangan & Kesimpulan \\
\hline NPV & Rp 201.232.547 & $>0$ usaha layak & Layak \\
\hline IRR & $34,9 \%$ & $\begin{array}{l}\text { > Tingkat Bunga maka } \\
\text { usaha layak }\end{array}$ & Layak \\
\hline B/C Ratio & $1,08 \%$ & $>1$ usaha layak & Layak \\
\hline PBP & 2,4 & $\begin{array}{l}\text { Jika }<\text { dibanding dengan } \\
\text { target kembalinya, maka } \\
\text { investasi layak. }\end{array}$ & Layak \\
\hline
\end{tabular}

Sumber: Data Primer yang diolah, 2020

Berdasarkan Tabel 1. Analisis kelayakan finansial menunjukkan bahwa usaha pengumpulan TBS Kelapa Sawit layak untuk diusahakan. Hal ini ditunjukkan oleh nilai NPV sebesar Rp 201.232.547, IRR sebesar $34,9 \%$, Net B/C sebesar $1,08 \%$ dan payback period 2,4 atau selama 2 tahun 4 bulan.

Saran bagi Pak Muhtar (pelaku usaha pengangkutan TBS) adalah aspekaspek yang mendukung pada usaha pengumpulan TBS Kelapa Sawit Bapak Muhtar dengan alternatif pengangkutan TBS Kelapa Sawit ke PKS dengan sewa angkutan truk ini menunjukkan usaha ini layak untuk dijalankan sehingga dapat di kembangkangkan lagi untuk kedepanya.Berdasarkan hasil analisis kelayakan finansial hasil dari analisis payback period yaitu 2 tahun 4 bulan. Nilai tersebut lebih pendek jika dibandingkan dengan umur dan target usaha yaitu selama 5 tahun. Sehingga memungkin untuk Bapak Muhtar sebagai pedagang pengumpul TBS Kelapa Sawit dapat menambah armada pengangkutan seperti truk, dengan membeli secara kredit maupun cash, dan second maupun baru.

\section{DAFTAR PUSTAKA}

Gittinger, JP. 1986. Analisa Ekonomi Proyek-Proyek Pertanian. Penerjemah Slamet Sutomo dan Komet Mangiri. Penerbit Universitas Indonesia. Jakarta.

Ibrahim, Y. 2003. Studi Kelayakan Bisnis. Edisi Revisi Rineka Cipta. Jakarta.

Kasmir, \& Jakfar, 2012. Studi Kelayakan Bisnis. Prenadamedia Group. Jakarta.

Nitisemito, Alex S. dan M. Umar Burhan. 2009. Wawasan Studi Kelayakan dan Evaluasi Proyek. Edisi Revisi. Cetakan Kedua. Bumi Aksara. Jakarta.

Umar, Husein. 2005. Studi Kelayakan Bisnis, Manajemen, Metode dan Kasus. PT Gramedia Pustaka Utama. Jakarta.

Warta,E. 2020. Indonesia Sang Jawara Ekspor CPO. (Tautan ini dapat diakeses melalui: https://www.wartaekonomi.co.id / read267889/ indonesia-sangjawara- ekspor-cpo- negara- 
Ario Sandika Putra, Evi Feronika, Trisna Anggreini

tujuannya. Diakses pada tanggal 20 Agustus

2020.

Weston, Fred, J dan Brigham, F, Eugene. 1990. Dasar-dasar Manajemen Keuangan. Edisi

Kesembilan. Penerbit Erlangga. Jakarta.
Analisis Kelayakan Pengumpulan Tandan Buah Segar Kelapa Sawit Menggunakan Sewa Angkutan Armada Truk Di Kecamatan Kotawaringin Lama Kabupaten Kotawaringin Barat 